\title{
A Study on the Social Welfare Application of the 4th Industrial Revolution :Focus on Social Welfare Major Student
}

\author{
Jeongwon Baik1), Heeeun Nam²), Yujin $\left.\mathrm{Im}^{3}\right)$, Jounghyeon Jang4), Eunsuk Bae5)
}

\begin{abstract}
How can this study apply to the Fourth Industrial Revolution and its technologies in social welfare? As a follow-up of the research on the 4th Industrial Revolution, to find out the implications for the application of social welfare through Focus Group Interview and literature studies on how various technologies can be applied to the social welfare site. According to the purpose of this study, two research methods were used for literature data related to the Fourth Industrial Revolution and Focus Group Interview research methods for exploratory research. As a result of the Focus Group Interview, the AI section raised the possibility of promoting resources and transferring information between communities. As a result of the Focus Group Interview, the AI section raised the possibility of promoting resources and transferring information between communities. The development of robots has a positive effect on the rehabilitation of clients and the guarantee of the right to move. The development of 3D printers is said to be easy for customizing the necessary equipment and providing the necessary goods for welfare centers. In the case of drones, they showed closeness with the site. In the big data and sharing economy, it is expected to quickly find out the welfare blind spots based on artificial intelligence big data and prevent them from being excluded. Was raised. In the future, social welfare expertise in the welfare field will not only be a convergence technology of various technologies, but also the reinforcement of expertise to practice client-centered human emotions, empathy, and emotion, and strengthen the skills of face-to-face service, creativity and management according to future changes. It was found that more and more necessary.
\end{abstract}

Keywords: Fourth Industrial Revolution, Social Welfare, Focus Group Interview, Case Study

Received(December 05, 2019), Review Result(1st: January 07, 2020, 2nd: February 24, 2020), Accepted(April 25, 2020)

1) (Researcher) Korea Youth Counselling \& Welfare Institute, 79 Centum jungang-ro, Haeundae-gu, Busan, Republic of Korea email: jwbaik99@gmail.com

2) (Professor, Corresponding Author) 49104 Dept. Social Welfare, Kosin Univ., 194 Wachi-Ro, Yeongdo-Gu, Busan, Korea email: henam@kosin.ac.kr

3) (Assistant Professor) 49104 Dept. Social Welfare, Kosin Univ., 194 Wachi-Ro, Yeongdo-Gu, Busan, Korea email: yjim@kosin.ac.kr

4) (Professor) 47230 Dong-Eui Institute of Technology., Division of Cosmetology, 54, Yangji-ro, Busanjin-gu, Busan, Korea email: jhjang@dit.ac.kr

5) (Assistant Professor) 49104 Dept. Social Welfare, Kosin Univ., 194 Wachi-Ro, Yeongdo-Gu, Busan, Korea email: coin21c@hanmail.net 


\section{Introduction}

The Fourth Industrial Revolution was publicized in earnest in 2016 by Klaus Schwab[1]. Since 2016 when the term of the Fourth Industrial Revolution began to spread, the rapid development of core technologies such as artificial intelligence (AI) and the stories that change the world are already talked too much around us[2]. This study began with the question of how the Fourth Industrial Revolution and its technologies can be applied to social welfare fields. Amid the consensus that changes of education and social welfare in response to rapidly changing social changes are important, we are to explore the implications of how various technologies can be applied to social welfare through Focus Group Interview and literature studies as a follow-up study of the 4th Industrial Revolution related studies from 2017.

\section{Research Method}

\subsection{Data Collection and Analysis Method}

This study used two research methods: Literature data related to the Fourth Industrial Revolution and Focus Group Interview Research Method for Exploratory Research. First, the purpose of this study is to find the applicability of the 4th Industrial Revolution Technology to social welfare and to provide an exploratory basis for the future direction. In order to achieve the research goal, FGI (Focus Group Interview) was conducted for 4 students in their doctor's course and 4 in their master's course who are currently taking future social welfare related classes. Second, we are to explore the possibility through the literature review. Recently, FGI research is increasing and is a research method that is drawing attention as an additional or new data collection method. It has the advantage that the core concepts are summarized by the dynamics within the group as consent and debate are exchanged among participants during the interview[3]. In this sense, the Focus Group Interview research method seems to be appropriate for the research on the new concept of '4th Industrial Revolution and Social Welfare'. Data collection method is as follows. In the case of capital research topics, the contents are vast and the concept is unfamiliar in the integration with the social welfare field, so the students are encouraged to review the open questionnaire and the video data on the 4th industrial revolution individually two weeks before the Focus Group Interview for the efficiency of the research. The guidelines before conducting this research are to make the structure of an interview clear and to facilitate the interview during the research. The semi-structured research 
questions are: 'Will the lives of the social welfare subjects be better by the 4th Industrial Revolution? 'What are the positive and negative effects of the social welfare studies due to the 4th Industrial Revolution?,' 'What are the changes in the social welfare field caused by the Fourth Industrial Revolution?'.

\subsection{FGI Research Results}

The results of Focus Group Interview research were classified into five categories of artificial intelligence, robots, 3D printers, drones, big data, and sharing economy, which were commonly presented in the Fourth Industrial Revolution and the opinions of Focus Group Interview participants were classified. According to the development of the 4th industrial revolution technology and the possibility of integrating it with the social welfare field, the artificial intelligence section raised the possibility of resource promotion and information transfer between communities. The development of robots had a positive effect on the rehabilitation of clients and the guarantee of the right to move, while the development of 3D printers made it easy to customize the necessary equipment and provide the necessary goods for welfare centers. Drones presented the closeness with the site. In the big data and sharing economy, welfare blind spots are quickly found based on AI big data and prevented from being excluded, and sharing of means of transportation, possibility of entering various fields, and efficient resource sharing among welfare institutions are expected.

[Table 1] Results of Focus Group Interview Analysis

\begin{tabular}{c|c}
\hline $\begin{array}{c}\text { 4th } \\
\text { Industrial } \\
\begin{array}{c}\text { Revolution } \\
\text { related } \\
\text { technology }\end{array}\end{array}$ & $\begin{array}{c}\text { Social welfare field } \\
\text { AI }\end{array}$ \\
$\begin{array}{c}\text { Increased learning ability through continuous knowledge acquisition } \\
\text { You can take charge of resource coordination between communities, } \\
\text { computerization, office work, and nutrition management in social welfare } \\
\text { institutions can be entrusted }\end{array}$ \\
$\begin{array}{c}\text { Expected improvement of work capacity and quality of services } \\
\text { Thevelopment of counseling services and quick checks of the subject's } \\
\text { health condition } \\
\text { Easy link of services that the subject needs } \\
\text { Companion, delivery of information } \\
\text { Accuracy of rating } \\
\text { Prevention of client's dementia }\end{array}$ \\
\hline
\end{tabular}




\begin{tabular}{|c|c|}
\hline Robot & $\begin{array}{c}\text { Assistance to client rehabilitation, guaranteed mobility rights } \\
\text { Development of assistive devices for rehabilitation treatment and daily life } \\
\text { 24-hour care is available and medical and educational services are provided } \\
\text { through remote support service } \\
\text { Reinforced convenience of nursing facilities } \\
\text { Home visit services for clients with disabilities }\end{array}$ \\
\hline $3 \mathrm{D}$ printer & $\begin{array}{l}\text { Customization of necessary equipment, easy to manufacture, reduced } \\
\text { professional manpower, service competition, production of necessary goods } \\
\text { Providing necessary items to welfare centers } \\
\text { Providing customized canes and wheelchairs } \\
\text { Providing customized aids for the individual characteristics of the disabled }\end{array}$ \\
\hline Drone & $\begin{array}{l}\text { Site supervision, goods delivery, medical drone, lunch delivery, delivery of } \\
\text { daily necessities } \\
\text { Increased convenience for getting the goods you need quickly } \\
\text { Emergency patient transportation is available when the delivery service is } \\
\text { increasing and more developed } \\
\text { CCTV to protect clients in a wider range }\end{array}$ \\
\hline Big data & $\begin{array}{l}\text { Prevention of welfare blind spots based on knowledge acquisition data of AI } \\
\text { Can receive objective information and provide customized service through } \\
\text { needs survey } \\
\text { Outreach for potential risk subjects }\end{array}$ \\
\hline $\begin{array}{l}\text { Sharing } \\
\text { economy }\end{array}$ & $\begin{array}{l}\text { Reduction of traffic jams, support of transportation expenses, entry into } \\
\text { various sites } \\
\text { Possible to share the means of transportation and the place for the program } \\
\text { The use of self-driving services makes it easy to transport emergency } \\
\text { patients, and the cost is reduced through sharing, thereby increasing the number } \\
\text { of service users } \\
\text { Resources sharing between welfare institutions }\end{array}$ \\
\hline
\end{tabular}

\subsection{Combination Cases of Social Welfare and Fourth Industrial Revolution}

AI emerged as a new technology field of national strategy. After the Obama Administration announced a national strategy for AI Research \& Development in 2016, many countries have selected $\mathrm{AI}$ as a national strategic technology sector and announced policies for R\&D, human resource development, and industrial promotion. In 2017, Canada's 'Pan Canada AI Strategy', Japan's 'AI Technology Strategy', China's 'Next Generation AI Plan', and 'Three-Year Action Plan' were established, followed by UK, Sweden, France, Australia, Germany and Korea's plans in 2018. Korea has also deliberated'AI R\&D strategy' through the 4th Industrial Revolution Committee and invested KRW 2.2 trillion by 2022 to secure world-class technology, train 50,000 talented people, lay the foundation for development and cooperation research and carry out large-scale AI public projects[4]. In addition to these trends of the times and the results of the 
FGI presented above, this paper is to examine the combination of the social welfare and the Fourth Industrial Revolution[5].

Case 1: Japan's Pepper Care Robot is a robot developed in collaboration with ND Software (Welfare Software Developer) and was tested by examining the scope of application as a care robot for the elderly with dementia. This robot is used to promote the health of the elderly by not only checking the drug use through simple conversations with the elderly, but also by doing recreational activities such as brain training.

Case 2: Chinese AI and IOT-based Nursing Home

As the first intelligent nursing home pilot service in Alibaba, a well-known technology company in China, it was used as a care pilot space using the intelligent network. The AI speaker facilitates the operation of facilities such as air conditioners and lighting etc., while the sensor also operates the facilities automatically for the elderly and users, and triggers alarms when risks are detected.

Case 3: Molly, a US telemedicine-based nursing assistant

It was developed by Sensely, a US venture company, and provided medical care and remote medical treatment for diseases such as patient monitoring and blood pressure measurement. This was used for video checkup based on the data by providing the notification of blood pressure measurement when accessing service from smartphone or tablet and sending data when measuring blood pressure with a separate machine.

Case 4: MyBom, a Korean Dementia Elderly Caring Robot and ICT Care Service

It is an AI-based social robot developed by the Korea Institute of Science and Technology (KIST) Dementia DTC Convergence Research Group. Its main purpose is to take care of dementia patients. They are mainly used for risk situations (falls, unauthorized outings) and information provision (meal time, medication, location guidance) in the daily life of patients with mild dementia. Since 2018, SK Telecom has conducted the 'Smart Home Dream House' project with social welfare corporations and local governments to support the disabled. This project aims to enhance the convenience of daily life for the disabled by providing and installing IOT interlocking devices such as switches, gas circuit breakers and AI speakers for free.

Case 5: In July 2019, the intensive health care model demonstration project using big data was started in Korea as part of community integrated care (community care leading project). This project used big data to identify the elderly and the disabled who require health care, and prepared a service provision model for each type and type of subjects who require health care[6]. 
Gradually developing from the time before the beginning of the Fourth Industrial Revolution to the present, the five cases discussed above have been used through a combination of social welfare and technology. In addition to the cases presented, companies began to use AI technology as a top priority in all areas as they implemented AI first strategies even more. With the various achievements and application cases of 2018 presented above, more and more attempts will be made in the future. As in the cases above, if AI replaces unskilled workers, more people will be hired for care and better pay will be provided. This is accompanied by the identity of the future in the value and role of care services of social welfare. IoT technology expands the possibility of service to welfare service subjects such as the elderly and the disabled who are not familiar with smart devices. The fact that things are connected to the Internet means that things become computers, which means that the information transmitted by things connected to the Internet may cause problems such as privacy security because it includes not only the simple state, but also the contents related to the person who uses the office work.

The development of technology, including AI and IoT, are newly applied to social changes such as elevated robot's skills, low fertility, aging. Service robots are classified into professional services and personal services. Professional service robots are used in various fields such as medical treatment, military, society, safety, distribution, banking, and hotels to improve efficiency and reduce costs. Personal service robots can be used for household chores, education, entertainment, and healthcare and get along with people in everyday life. Social robots are emotion-centered to communicate and interact with people. It is meaningful to apply and utilize these emotion-centered social robots to the vulnerable including the elderly living alone and the disabled in the social welfare field. The AI voice recognition service is applied to the speaker, and the camera can recognize the face and turn the body to the direction of the user or change the facial expression and start a conversation first.

Social robots assist with home health care according to aging, learning for children, and people in need, while home healthcare robots recognize the voices and faces of family members to provide them with drugs or nutrients they need in time, answer health-related questions and connect experts if needed. The interest in robots as an alternative to emotional communication is increasing, and robots can play a useful role in those who are tired of establishing and maintaining social relationships as non-face-to-face communication that eases the burden of conversations. 


\section{Conclusion}

This study examined the Focus Group Interview and the cases in terms of the prediction that the application of various technologies of the 4th Industrial Revolution to social welfare is currently developed and the technologies can be commercialized and be applied to social welfare fields. Each technology representing the Fourth Industrial Revolution is not an independent keyword but is organically compounded and applied to new technologies, so there is a limit to dividing by keyword.

What can be discussed in common through each keyword is that AI, social robots, and IoT coexist with the development, convergence, and hyper-connection of technology in each field. In conclusion, although it is difficult to clearly connect the vast 4 th industrial revolution technologies to social welfare, the possibility of using some of the meaningful technologies was examined and the future was forecasted at the convenience of the researcher.

Many experts agree that the industrial revolution had largely replaced physical labor with machines, while AI could replace both our intelligence and physical capabilities, and that scale and speed would be very fast. Deep learning-based AI technology is making technological progress with new achievements in various fields, and many countries have announced various policies such as $\mathrm{R} \& \mathrm{D}$, human resources, and industry using $\mathrm{AI}$ as a national strategy[7]. The convenience of technology is necessary for the enjoyment of humanity, but it must also be concerned about the happiness of those who enjoy it. Technology is a tool to realize our imagination, and we must pay attention to the practical aspects that will change our daily lives rather than the huge discourse of the Fourth Industrial Revolution. And in the waves of change, we need to think about what is comfortable and how to be happy. We must also think about not only convenience, but also the opportunities and crises that arise from the reorganization of new ecosystems.

Workers in social welfare institutions may think that $\mathrm{AI}$ robots may not replace human jobs in the fourth industrial revolution. This may be a desire of majors and service providers working in the field. In Employment Future written by Karl Frey and Michael Osborne, they said that creativity and social intelligence remain for human beings, and creativity and business management are areas which are difficult to be replaced by robots and AI[8]. Social welfare expertise, which needs to be strengthened further, may strengthen the social welfare identity of the changing future only when high-touch emotional education such as human relations, communication, and empathy services should be strengthened. 
According to Klaus Schwab, the 4th Industrial Revolution has changed the traditional concept of occupation, so self-development must be made to change 3-4 jobs in life. Given the increased employment opportunities for people with advanced skills, it is necessary to reinforce the expertise to practice the service of human emotion, empathy, and impression centered on clients and to strengthen the technology of face-to-face service, creativity and management ability according to the future change in addition to the convergence technology of various technologies[9].

\section{References}

[1] Schwab, K., The Fourth Industrial Revolution: what it means, how to respond, World Economic Forum, (2016)

[2] Hong S. M., Fourth Industrial Revolution and the Future Beyond, FUTURE HORIZON, (2018), No.37.

[3] Krueger, R. A., Analyzing and reporting focus group results, Sage publishing, (1997)

[4] Lee M. H., Read the future, Forward, (2018)

[5] Fourth Industrial Revolution and Smart Welfare 4.0., Forum Report, KCERN, (2018), Vol.48, pp.213-258.

[6] http://www.newspim.com/news/view/, May 30 (2019)

[7] Cha. D. W., Kim. S. W., Job Killer: The Industrial Revolution, the Future of Jobs Changed by Robots and AI, Hans Media, (2016)

[8] Frey, C. B., Osborne, M. A., The future of employment: how susceptible are jobs to computerisation, University of Oxford, (2013)

[9] Ko. H. S., Kim. Y. D., Fourth Industrial Revolution, Floating occupations Losing occupations, Miders, (2017), Vol.2, pp.96-97. 